\title{
Short Communication Note: Conflict and Hidden Cost
}

\section{Kanchan Thapa ${ }^{1}$}

The Economist says "Nothing comes free; everything in this world comes with a price tag...there is no free lunch as such". I used to argue that ethics, humanity and social lenience are things that have no price tags as such. Was I wrong when I made this argument? I am a young aspiring scientist trying to make some difference in the field of wildlife science. I always believed in hard core science which was until I came up with the issue of Human Wildlife Conflict. Issues with more hidden costs than hard core science cares to explain.

Examples of Human Wildlife Conflict have been well documented in literature, research papers and journals and the possible causes behind these issues (like habitat degradation/ fragmentation etc) have been well articulated using the windows of hard core science. Mitigation measures have been applied in some sense but have not been effective dealing with socially inbound animals. Hence, measures have been practiced only as a temporary measure rather than a long lasting strategy to eliminate the problem.

Damage to property, human casualties; crop depredation have been the major ramifications of conflict arising due to the confrontation between humans and elephants. Regardless of the number of wild elephants venturing into an agricultural land, the extent of damages incurred or experienced is similar to the damage incurred by a single elephant.

It is but natural for a farmer owning a ropani of land, spending his day and night nurturing field for rich cereals to feel resentment and hatred towards the mighty beast. Compensation schemes help to replace his direct costs involved but what about his hidden costs? Natural Resource Managers and researchers often try to ignore the hidden costs involved in human elephant conflict situations. The loss of crops often tries to undermine the aspiration of people for a better life. In high conflict areas such as Bardia, the average household loses about Rs 10,000 annually, where as same cost would be cumulative in building better life for farmers. There has been a break in leading normal life where further cost has been eaten up in providing better protection measures which could other wise be spent in improving the quality of life.

A Mother loses her infant baby crushed by a marauding elephant, the highest act of cruelty from a mighty beast. What would be the compensation mechanism for her money? How can we expect to have a positive attitude towards the animal in such circumstances? These are never ending sources of stress for these families where the direct cost is too meager to substantiate a loss.

Beside crop depredation, loss/damage of physical infrastructure has also been high. People lose their houses and are left homeless. What choices could they have than to have negative

\footnotetext{
$\bar{I}$ Senior Research Officer, WWF Nepal Program, Kathmandu, Nepal, kanchan.thapa@wwfnepal.org
} 
feeling towards the animals? More to that, a home is the ultimate symbol of security in our societies. When a wild animal threatens or destroys that security, people will resort to retaliatory measures. In Jhapa alone, 13 elephants were killed in retaliation in the period between 1980-2001(Yadav 2003).

Peoples' aspiration for a better life, security and stress free environment are all hidden costs involved in living with elephants. These must be dealt in a manner to increase their tolerance towards wildlife in human dominated landscapes.

\section{$\mathrm{X} \times \mathrm{X}$}

Bird Conservation Nepal (BCN) is the largest and oldest civil society organization dedicated to the interests of ornithologists, birdwatchers and conservationists in Nepal. It seeks to: promote an interest in birds among the general public; encourage research on bird biology and ecology; identify the major threats to birds and act to conserve birds and their habitats. It also provides the most authentic information on birds and their habitats across Nepal.

$\mathrm{BCN}$ is a membership organization at present supported by a Founder President, 16 patrons, 98 life members and several ordinary members. The major strength of the organization is the varied membership, which includes students, teachers, professionals, bird enthusiasts, conservationists, and the general public.

$\mathrm{BCN}$ recognizes the value of birds and promotes the participation of people as future stewards to attain long-term conservation goals. We do this through a variety of projects. If you would like to learn about what we are doing please visit our website.

BCN presently has 9 core staff and 12 project staff but relies on the invaluable work of volunteers and supporters. Bird Conservation Nepal would appreciate and welcome any kind of help that one can offer. For further information please contact us at:

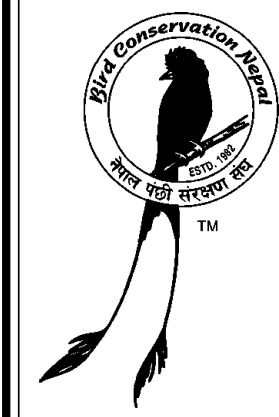

\section{Bird Conservation Nepal}

PO Box 12465,

Lazimpat Kathmandu, Nepal

Email: bcn@mail.com.np

Website: www.birdlifenepal.org

Tel 4417805, 4420213

Fax 4413884 